\title{
Terminology of Dental Caries and Dental Caries Management: Consensus Report of a Workshop Organized by ORCA and Cariology Research Group of IADR
}

\author{
Vita Machiulskiene ${ }^{a}$ Guglielmo Campus ${ }^{\text {b, c }}$ Joana Christina Carvalho ${ }^{d}$ \\ Irene Dige $^{\mathrm{e}}$ Kim Rud Ekstrand $^{\mathrm{f}}$ Anahita Jablonski-Momeni ${ }^{\mathrm{g}}$ Marisa Maltz $^{\mathrm{h}}$ \\ David J. Manton ${ }^{\mathrm{i}}$ Stefania Martignon ${ }^{\mathrm{j}, \mathrm{k}} \quad$ E. Angeles Martinez-Mier ${ }^{\prime} \quad$ Nigel B. Pitts ${ }^{\mathrm{j}}$ \\ Andreas G. Schulte ${ }^{m}$ Christian H. Splieth ${ }^{n}$ Livia Maria Andaló Tenuta ${ }^{\circ}$
}

Andrea Ferreira Zandona ${ }^{p}$ Bente Nyvad $^{\mathrm{e}}$

\begin{abstract}
${ }^{a}$ Clinic of Dental and Oral Pathology, Faculty of Odontology, Lithuanian University of Health Sciences, Kaunas, Lithuania; ${ }^{b}$ Klinik für Zahnerhaltung, Präventiv- und Kinderzahnmedizin Zahnmedizinische Kliniken (ZMK), University of Bern, Bern, Switzerland; ' ${ }^{C}$ Department of Surgery, Microsurgery and Medicine Sciences, School of Dentistry, University of Sassari,

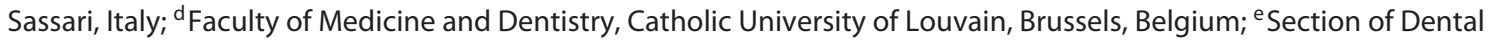
Pathology, Operative Dentistry and Endodontics, Department of Dentistry and Oral Health, University of Aarhus, Aarhus, Denmark; fSection of Cariology and Endodontics, Department of Odontology, Faculty of Health and Medical Sciences, University of Copenhagen, Copenhagen, Denmark; ${ }^{9}$ Department of Orthodontics, Dental School, Philipps-University Marburg, Marburg, Germany; hepartment of Preventive and Social Dentistry, Faculty of Odontology, Federal University of Rio Grande do Sul, Porto Alegre, Brazil; 'Growth and Development Section, Melbourne Dental School, University of Melbourne, Melbourne, VIC, Australia; 'Dental Innovation and Translation Hub, Faculty of Dentistry, Oral and Craniofacial Sciences, King's College London, London, UK; ${ }^{k}$ UNICA - Caries Research Unit, Research Vice-rectory, Universidad El Bosque, Bogotá, Colombia; 'Department of Cariology, Operative Dentistry and Dental Public Health, Indiana University

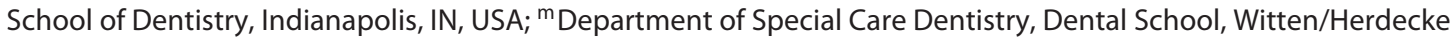
University, Witten, Germany; ${ }^{n}$ Section of Preventive and Pediatric Dentistry, University of Greifswald, Greifswald, Germany; ${ }^{\circ}$ Department of Cariology, Restorative Sciences and Endodontics, School of Dentistry, University of Michigan, Ann Arbor, MI, USA; P Department of Comprehensive Care, School of Dental Medicine, Tufts University, Boston, MA, USA
\end{abstract}

\section{Keywords}

Dental caries · Dental caries management · Dental caries terms $\cdot$ Consensus

Letter to the Editor: Gruythuysen RJM, van Loveren C, Burgersdijk RCW. NOCTP and NRCT Are Not Complete without Tailored Motivational Communication. Caries Res. 2021. DOI: 10.1159/000514022. Reply: Machiulskiene V, Nyvad B. Reply to Letter "NOCTP and NRCT Are Not Complete without Tailored Motivational Communication". Caries Res. 2021. DOI: 10.1159/000514021.

\section{KARGER}

(c) 2019 S. Karger AG, Basel

E-Mail karger@karger.com

www.karger.com/cre

\begin{abstract}
A 2-day workshop of ORCA and the IADR Cariology Research Group was organized to discuss and reach consensus on definitions of the most commonly used terms in cariology. The aims were to identify and to select the most commonly used terms of dental caries and dental caries management and to define them based on current concepts. Terms related to definition, diagnosis, risk assessment, and monitoring of dental caries were included. The Delphi process was used to
\end{abstract}


establish terms to be considered using the nominal group method favored by consensus. Of 222 terms originally suggested by six cariologists from different countries, a total of 59 terms were reviewed after removing duplicates and unnecessary words. Sixteen experts in cariology took part in the process of reaching consensus about the definitions of the selected caries terms. Decisions were made following thorough "round table" discussions of each term and confirmed by secret electronic voting. Full agreement (100\%) was reached on 17 terms, while the definitions of 6 terms were below the agreed $80 \%$ threshold of consensus. The suggested terminology is recommended for use in research, in public health, as well as in clinical practice.

(c) 2019 S. Karger AG, Basel

\section{Introduction}

A joint workshop of ORCA and the IADR Cariology Research Group on the Terminology of Dental Caries and Dental Caries Management was organized on February 6-7, 2019 in Frankfurt, Germany, in order to discuss and reach consensus on the definitions of the most commonly used terms in cariology. The inspiration to organize the present workshop was stimulated by continuous ongoing discussions among researchers, clinicians, public health professionals, and policy makers regarding the most appropriate terms to describe conditions and characteristics of dental caries and related matters. The organizers of the workshop agreed that the benefits of a common terminology would include facilitating researchers to share concepts, to document conditions as well as to interpret them in the same way, and to ease communication with clinicians.

Thus, the aims of the workshop were: (i) to identify the available terms in the literature used to describe dental caries and related matters, (ii) to select the most commonly used terms and review their definitions, based on the current concepts, and (iii) to discuss and agree upon the most appropriate terms and definitions. Terms related to the definition, diagnosis, risk assessment, and monitoring of dental caries were included.

\section{Methods}

The Delphi process was used to establish the terms or statements and definitions to be considered using the nominal group method favored by consensus. Prior to the workshop, a group of six experts suggested by the ORCA Board independently provided commonly used terms related to dental caries. The total number of terms suggested was 222. After removing duplicates and unnecessary words (e.g., Ex vivo, In vitro, In vivo, Magnification aid, Prognosis, Diet, Fluorapatite, Fluoride, Micronutrient, Saliva, Salivary flow, Starch, Sucrose, Sugar), 121 terms were taken forward by the Editor-in-Chief of Caries Research, the official journal of ORCA. This number was then revised by several working group members (V.M., B.N., and J.C.C.) and further reduced to 60 by removing synonymous terms (e.g., Caries, Dental caries, Caries disease) and the terms that do not relate directly to dental caries (e.g., Coding, Detection aid). The provisional definitions of the selected terms were provided by the chairpersons of the working group (V.M. and B.N.) and circulated to the group of 17 experts who independently decided on the appropriateness of the definitions. In total, 16 researchers with considerable research expertise in cariology participated in the workshop and in the process of reaching consensus about the definitions of the selected caries terms. Following discussions at the workshop, the final number of terms ended up at 59.

A priori, consensus was established as $80 \%$ agreement among the participating experts on the definition of each term. The decisions were made following thorough "round table" discussions of each term, and confirmed by secret voting using an electronic program [Mentimeter, 2019]. The consensus percentage agreement is presented in parentheses next to each term.

\section{Results}

The definitions of 59 terms related to dental caries and dental caries management were reviewed. Full agreement (100\%) was reached on 17 terms, while the definitions of six terms (Caries incidence, Rampant caries, Visual detection of caries lesion, Ultra-conservative caries treatment, Therapeutic sealing) were below the agreed $80 \%$ threshold of consensus.

\section{Definitions of Dental Caries as a Disease}

Dental Caries (100\%)

Dental caries is a biofilm-mediated, diet modulated, multifactorial, non-communicable, dynamic disease resulting in net mineral loss of dental hard tissues [Fejerskov 1997; Pitts et al., 2017]. It is determined by biological, behavioral, psychosocial, and environmental factors. As a consequence of this process, a caries lesion develops.

\section{Caries Diagnosis (94\%)}

Caries diagnosis is the clinical judgement integrating available information, including the detection and assessment of caries signs (lesions), to determine presence of the disease. The main purpose of clinical caries diagnosis is to achieve the best health outcome for the patient by selecting the best management option for each lesion type, to inform the patient, and to monitor the clinical course of the disease [Nyvad et al., 2015]. 
Caries Activity (100\%)

Caries activity is a concept that reflects the mineral balance, in terms of net mineral loss, net mineral gain, or stasis over time. Caries active implies caries initiation/ progression; caries inactive implies caries arrest/regression [Thylstrup et al., 1994].

Prognosis of Caries (94\%)

Prognosis of caries is the likely or expected course of dental caries.

\section{Caries Free (94\%)}

Caries free implies that there are no detectable signs of dental caries. It is a label that often leads to misunderstanding. This term should not be used without clearly indicating the threshold level.

\section{Cavity Free (81\%)}

Cavity free implies that there are no detected cavities in dentine. However, thorough clinical examination may reveal the presence of non-cavitated and/or micro-cavitated carious lesions.

\section{Caries Care/Management/Control (100\%)}

Caries care/management/control are actions taken to interfere with mineral loss at all stages of the caries disease [Nyvad and Fejerskov, 2015], including non-operative and operative interventions/treatments. Because of the continuous de/remineralization processes, caries control needs to be continued throughout the life course. The terms caries care/management/control may be more appropriate than the term Caries prevention.

\section{Caries Prevention (88\%)}

Caries prevention traditionally meant inhibition of caries initiation, otherwise called primary prevention. Primary, together with secondary and tertiary prevention, comprising non-operative and operative treatments, are now summarized under Caries care/management/control.

\section{Demineralization (94\%)}

Demineralization is the loss of tooth mineral, due to acids. In dental caries, this process is biofilm-mediated, while in erosion, the acid comes from other sources.

\section{Remineralization (100\%)}

Remineralization is the net gain of mineral in previously demineralized tissue. The word remineralization can be misleading as it does not imply that the lesion has regained its original mineral content.

Terminology of Dental Caries and Dental Caries Management
Dental Biofilm (100\%)

Dental biofilm is a consortium of microorganisms that stick to a tooth surface. The microorganisms are embedded in an extracellular polymeric matrix (modified from Hall-Stoodley et al. [2004]).

Dental Plaque (94\%)

Dental plaque is a clinical term used commonly when referring to the dental biofilm.

\section{Cariogenic (100\%)}

Cariogenic describes substrates or microorganisms capable of promoting dental caries.

Cariogenicity (100\%)

Cariogenicity is the potential of substrates or microorganisms to promote dental caries.

\section{Cariostatic (88\%)}

Cariostatic describes substances or procedures capable of arresting dental caries.

\section{Definitions of Terms Used in Dental Caries}

Epidemiology

Caries Experience (94\%)

Caries experience is the number of teeth/surfaces that have caries lesions (at a specified threshold), restorations, and/or are missing due to caries, accumulated by an individual, up to a designated point in time. Traditionally, it has been measured by means of DMFT/S ( $\mathrm{dmft} / \mathrm{s}$ ) at varying detection levels. New models and indices are being explored internationally.

\section{Caries Prevalence (94\%)}

Caries prevalence is, in a strict sense, the number/ proportion of individuals with caries in a given population at a specified threshold, at a designated point in time. Case definitions are often misunderstood and are necessary. In many studies, the prevalence of caries experience has been reported. Other specific examples of case definitions include reporting of total (untreated and treated) caries lesions in primary and permanent teeth or untreated caries, which includes lesions in primary and permanent teeth that have not received appropriate treatment [Fleming and Afful, 2018].

\section{Caries Incidence (69\%)}

Caries incidence is, in a strict sense, the number/proportion of individuals with new or progressing caries at a 
specified threshold in a given population, detected during a given period.

Caries Surveillance (100\%)

Caries surveillance is the ongoing, systematic collection, analysis, and interpretation of caries data, essential to the planning, implementation, and evaluation of public health practice, and the timely dissemination of these data to those who need to know so that action can be taken (modified from Last [2001]).

Caries Risk (94\%)

Caries risk is the probability that caries lesions will appear or progress if conditions remain the same within a stated period of time (modified from Last [2001]). Caries risk is a proxy for the true outcome (new caries lesions or progression), which can only be validated over time.

\section{Caries Risk Factor/Determinant (94\%)}

Caries risk factor/determinant is an environmental, behavioral, or biological factor confirmed by temporal sequence, usually in longitudinal studies, which, if present, directly increases the probability of caries occurrence. The risk factor is part of the causal chain [Burt, 2001].

\section{Modifiable Risk Factor (94\%)}

Modifiable risk factor is a determinant that can be modified by intervention, thereby reducing the probability of caries.

Caries Risk Indicator/Marker (94\%)

Caries risk indicator/marker is a characteristic associated with increased probability of caries or increased occurrence of caries (modified from Last [2001]). A risk indicator is not causally associated with the disease.

\section{Caries Risk Management (88\%)}

Caries risk management is the measures taken to reduce the caries risk to which an individual or population is subject (modified from Last [2001]).

\section{Definitions of Terms Related to the Dental Caries \\ Lesion \\ Caries Lesion (88\%)}

Caries lesion is the clinical sign of caries. Caries lesions can be categorized according to their anatomical location on the tooth (coronal or root/cementum surface), their severity (e.g., non-cavitated, cavitated), depth of penetration into the tissue (e.g., enamel, dentin, pulp), and their activity status (active, inactive).
Caries Lesion Detection (94\%)

Caries lesion detection is the identification of the signs of dental caries. Caries lesions can be detected clinically at various detection thresholds and stages, e.g., non-cavitated, micro-cavitated, and cavitated. Caries lesions can also be detected by supplementary detection tools, such as radiography and optical and electrical methods. In vitro caries lesion detection includes histology, transmission and scanning electron microscopy, as well as confocal laser scanning microscopy.

\section{Caries Lesion Severity Assessment (81\%)}

Caries lesion severity assessment is the staging of the process of net mineral loss progressing from small lesions to increasing degrees of tooth destruction through to involvement of dental pulp. It can be achieved using a range of classification methods and systems. Examples include clinical staging into non-cavitated, micro-cavitated, and cavitated lesions [Ekstrand et al., 1998; Nyvad et al., 1999], clinical and radiographic staging into initial, moderate, and extensive lesions [Pitts et al., 2013], and clinical staging from non-cavitated lesions to pulpal sepsis [Frencken et al., 2011].

\section{Caries Lesion Activity Assessment (88\%)}

Caries lesion activity assessment seeks to differentiate lesions deemed caries active from lesions deemed caries inactive in order to provide optimal care planning where there is a focus on arresting active lesions. Inactive lesions and sound surfaces should receive background level care and appropriate monitoring. Several systems have defined the process to assess activity.

Activity status of a caries lesion is defined by surface characteristics [Thylstrup et al., 1994]. Clinical surface features, such as change of texture, translucency, and color, and other factors such as presence of thick plaque and plaque stagnation area as well as gingivitis discriminate the likelihood of a lesion progressing or non-progressing/ arrested [Carvalho et al., 1989, 2017; Ekstrand et al., 1998, 2007; Nyvad et al., 1999, 2003; Ismail et al., 2015; Nyvad and Baelum, 2018; Drancourt et al., 2019]. Different systems include different combinations of these characteristics, with varying weight.

\section{Initial Caries Lesion (100\%)}

Initial caries lesion is a frequently used term for noncavitated caries lesion. Although the term implies an early-stage lesion, the lesion could have been present in the mouth for a lifetime. The term refers to the stage of severity and does not inform about lesion activity. 
White-Spot Lesion = "White Spot" (94\%)

White-spot lesion ("white spot") is a popular term for non-cavitated lesions in the past. The term refers solely to the color of the lesion, has no bearing on the activity of the lesion, and may be confused with other types of pathology such as dental fluorosis or MIH.

\section{Sound Enamel/Dentin (100\%)}

Sound enamel/dentin is tooth structure without clinically detectable alterations of the natural translucency, color, or texture.

\section{Primary Caries (100\%)}

Primary caries is a caries lesion on previously sound tooth surface.

Secondary Caries/Recurrent Caries (88\%)

Secondary caries/recurrent caries is a caries lesion developed adjacent to a restoration.

Residual Caries (94\%)

Residual caries is a demineralized carious tissue left in place before a restoration is placed.

"Hidden" Caries (94\%)

"Hidden" caries is a caries lesion in dentine missed on visual inspection but detected radiographically or with other detection devices. In the context of present diagnostic knowledge, it is a historic and confusing term.

\section{Rampant Caries (69\%)}

Rampant caries is a historic term used to describe multiple caries lesions in the same patient, often used in association with early childhood caries or radiation caries.

Early Childhood Caries (94\%)

Early childhood caries is the early onset of caries in young children with often fast progression, which can finally result in complete destruction of the primary dentition. An epidemiological definition of early childhood caries is the presence of one or more decayed (non-cavitated or cavitated lesions), missing (due to caries), or filled surfaces in any primary tooth of a child under age of 6 [Drury et al., 1999; Pitts et al., 2019].

Due to the frequent consumption of carbohydrates, especially sugars, and inadequate to absent oral hygiene in small children, early childhood caries demonstrates an atypical pattern of caries attack, particularly on smooth surfaces of upper anterior teeth [Wyne, 1999].

Terminology of Dental Caries and Dental Caries Management
Caries Lesion Transition (100\%)

Caries lesion transition is a change in caries lesion severity and/or activity stage in response to changes of lesion environment, for example mediated by caries control measures or changes in life style.

\section{Visual Detection of Caries Lesion (69\%)}

Visual detection of caries lesion is the identification of the presence of a lesion visually.

\section{Tactile Assessment (81\%)}

Tactile assessment is the atraumatic tactile evaluation of the surface integrity and texture of a caries lesion by use of a dental manual instrument. It should not be confused with the historical practice of lesion detection by catching of the probe (no longer recommended).

Radiographic Detection (100\%)

Radiographic detection is the identification of a radiolucency interpreted as a caries lesion on a dental radiograph.

\section{Definitions of Terms Related to Management of Caries} or Caries Lesions

Caries Lesion Monitoring (100\%)

Caries lesion monitoring is an episodic assessment of the effect of an intervention or the natural behavior on the clinical and/or radiographic status of a caries lesion (modified from Last [2001]).

\section{Non-Operative Caries Treatment/Management/}

Control/Care (81\%)

Non-operative caries treatment/management/control/care are non-surgical measures interfering with the initiation of new caries lesion and the rate of caries lesion progression [Carvalho et al., 1992]. This treatment aims to keep the caries process at subclinical level and/or arrest caries lesion progression at the clinical/radiographic level [Carvalho et al., 2004]. The key elements can include brushing with fluoride toothpaste, other fluoride treatments, dietary modification, oral hygiene measures, etc. (sealing/infiltration are not unanimously recognized as non-operative treatment measures, but they are another non-surgical way of managing caries [see below]).

\section{Operative (Restorative) Caries Treatment (Care)}

(94\%)

Operative (restorative) caries treatment (care) is a surgical intervention to place a restoration to control caries, to aid biofilm control, and typically to restore form and function. 


\section{Non-Restorative/Non-Operative Cavity Treatment} $(88 \%)$

Non-restorative/non-operative cavity treatment is the approach to make the cavitated caries lesions accessible to tooth cleaning by removal of overhanging enamel margins [Hansen and Nyvad, 2017; Santamaria et al., 2017].

Topical Fluorides (100\%)

Topical fluorides are all methods of fluoride applied locally to teeth. They can be divided into self-applied (toothpaste, rinses, gels) or professionally applied (gels, varnishes, foams, solutions).

Systemic Fluorides (94\%)

Systemic fluorides are ingested fluorides. Historically this term referred to a supposed systemic effect. Currently, these methods of fluoride delivery such as fluoridated water and salt are used as public health measures that act through a topical effect when in contact with teeth.

Minimal Intervention Dentistry (81\%)

Minimal intervention dentistry is a holistic caries management philosophy that integrates caries lesion control and minimal operative intervention. The main objective is tissue preservation, including early caries detection and non-operative treatment, combined with minimally invasive restorative procedures [Frencken et al., 2012].

Preventive Sealant/Sealing (94\%)

Preventive sealant/sealing is the application of a thin physical barrier over a clinically sound caries predilection site, in order to prevent the initiation of a caries lesion. These can be applied to pits, fissures, and fossae using resin composite or glass ionomer cement.

Therapeutic Sealant/Sealing (75\%)

Therapeutic sealant/sealing is the application of a thin physical barrier over a caries lesion in order to prevent its progression. These can be applied to pits, fissures, fossae, and smooth surfaces [Martignon et al., 2006; Alkizy et al., 2009] using resin composite or glass ionomer cement.

\section{Caries Infiltration (94\%)}

Caries infiltration is a micro-invasive intervention by which the pores of a non-cavitated caries lesion are infiltrated with low-viscosity resin after treating the surface with hydrochloric acid [Paris et al., 2007].
Atraumatic Restorative Treatment (88\%)

Atraumatic restorative treatment is the tissue-saving caries management approach that uses hand instruments for opening caries cavities and removing decomposed carious dentine, followed by restoration with a high-viscosity glass ionomer. The technique does not require access to electrically driven equipment and running water [Frencken et al., 1996].

\section{Ultraconservative Caries Treatment (75\%)}

Ultraconservative caries treatment is a term used to define the method of bonded and sealed restorations placed directly over frank cavitated carious lesions extending into dentine [Mertz-Fairhurst et al., 1998].

\section{Caries Removal (88\%)}

Caries removal is removal of carious tissue by the use of burs, hand excavators, or other techniques.

Complete Caries Removal/Non-Selective Caries

Removal to Hard Dentine (81\%)

Complete caries removal/non-selective caries removal to hard dentine is excavation to hard dentine in the entire cavity. This technique is no longer recommended [Innes et al., 2016].

\section{Partial Caries Removal (100\%)}

Partial caries removal is an excavation method by which carious dentine is removed from the peripheral walls of a deep cavitated caries lesion (excavated to hard dentine), followed by partial removal of soft dentine from the pulpal wall with hand excavator [Bjørndal et al., 1997; Maltz et al., 2018] or round bur. Treatment is indicated for deep dentine lesions to avoid pulp exposure.

Selective Caries Removal to Soft Dentine (100\%)

Selective caries removal to soft dentine is an alternative term for partial caries removal [Innes et al., 2016].

\section{Selective Caries Removal to Firm/Leathery Dentine}

(94\%)

Selective caries removal to firm/leathery dentine is the excavation to firm/leathery dentine (physically resistant to hand excavation) in the pulpal aspect of the cavity. Periphery of the cavity should be excavated to hard dentine [Innes et al., 2016].

Stepwise Caries Removal (94\%)

Stepwise caries removal is the caries excavation in two (or more) steps, with a time interval between the steps, to
Machiulskiene et al. 
stimulate mineral deposition in the dentine prior to final excavation [Bjørndal et al., 1997]. The first step is partial caries excavation followed by additional caries removal to firm dentine at a later date [Innes et al., 2016].

\section{Conclusion}

In this consensus workshop, the definitions of the most commonly used terms related to dental caries and dental caries management were discussed, updated, and agreed on. The revised terms were based on current concepts published in the international scientific literature and on experts' opinions. The suggested terminology is recommended for the use in research, in the public health field, as well as in clinical practice. A regular update of the terms is advisable in order to reflect up-to-date scientific standard.

\section{Acknowledgements}

The consensus workshop was sponsored by The European Organization for Caries Research (ORCA). Additional financial support was provided by Karger Publishers, the Cariology Research Group of the International Association for Dental Research (IADR), Procter and Gamble, and Colgate Palmolive.

\section{Disclosure Statement}

The authors declare that they have no conflicts of interest to disclose.

\section{References}

Alkilzy M, Berndt C, Meller C, Schidlowski M, Splieth C. Sealing of proximal surfaces with polyurethane tape: a two-year clinical and radiographic feasibility study. J Adhes Dent. 2009 Apr;11(2):91-4.

Bjørndal L, Larsen T, Thylstrup A. A clinical and microbiological study of deep carious lesions during stepwise excavation using long treatment intervals. Caries Res. 1997;31(6):411-7.

Burt BA. Definitions of risk. J Dent Educ. 2001 Oct; $65(10): 1007-8$.

Carvalho JC, Ekstrand KR, Thylstrup A. Dental plaque and caries on occlusal surfaces of first permanent molars in relation to stage of eruption. J Dent Res. 1989 May;68(5):773-9.

Carvalho JC, Mestrinho HD, Oliveira LS, Varjão MM, Aimée N, Qvist V. Validation of the Visible Occlusal Plaque Index (VOPI) in estimating caries lesion activity. J Dent. 2017 Sep;64: $37-44$.

Carvalho JC, Thylstrup A, Ekstrand KR. Results after 3 years of non-operative occlusal caries treatment of erupting permanent first molars. Community Dent Oral Epidemiol. 1992 Aug; 20(4):187-92

Carvalho JC, Van Nieuwenhuysen JP, Maltz M. Traitement non-opératoire de la carie dentaire. Real Clin 2004;15:235-48.

Drancourt N, Roger-Leroi V, Martignon S, Jablonski-Momeni A, Pitts N, Doméjean S. Carious lesion activity assessment in clinical practice: a systematic review. Clin Oral Investig. 2019 Apr;23(4):1513-24.
Drury TF, Horowitz AM, Ismail AI, Maertens MP, Rozier RG, Selwitz RH. Diagnosing and reporting early childhood caries for research purposes. A report of a workshop sponsored by the National Institute of Dental and Craniofacial Research, the Health Resources and Services Administration, and the Health Care Financing Administration. J Public Health Dent. 1999;59(3):192-7.

Ekstrand KR, Martignon S, Ricketts DJ, Qvist V. Detection and activity assessment of primary coronal caries lesions: a methodologic study. Oper Dent. 2007 May-Jun;32(3):225-35.

Ekstrand KR, Ricketts DN, Kidd EA, Qvist V, Schou S. Detection, diagnosing, monitoring and logical treatment of occlusal caries in relation to lesion activity and severity: an in vivo examination with histological validation. Caries Res. 1998;32(4):247-54.

Fejerskov O. Concepts of dental caries and their consequences for understanding the disease. Community Dent Oral Epidemiol. 1997 Feb; 25(1):5-12.

Fleming E, Afful J. Prevalence of total and untreated dental caries among youth: United States 2015-2016. NCHS Data Brief, no 307. Hyattswille (MD): National Center for Health Statistics; 2018.

Frencken JE, de Amorim RG, Faber J, Leal SC. The Caries Assessment Spectrum and Treatment (CAST) index: rational and development. Int Dent J. 2011 Jun;61(3):117-23.

Frencken JE, Peters MC, Manton DJ, Leal SC, Gordan VV, Eden E. Minimal intervention dentistry for managing dental caries - a review: report of a FDI task group. Int Dent J. 2012 Oct;62(5):223-43.
Frencken JE, Pilot T, Songpaisan Y, Phantumvanit $\mathrm{P}$. Atraumatic restorative treatment (ART): rationale, technique, and development. J Public Health Dent. 1996;56(3 Spec No): $135-40$.

Hall-Stoodley L, Costerton JW, Stoodley P. Bacterial biofilms: from the natural environment to infectious diseases. Nat Rev Microbiol. 2004 Feb;2(2):95-108.

Hansen NV, Nyvad B. Non-operative control of cavitated approximal caries lesions in primary molars: a prospective evaluation of cases. J Oral Rehabil. 2017 Jul;44(7):537-44.

Innes NP, Frencken JE, Bjørndal L, Maltz M, Manton DJ, Ricketts D, et al. Managing carious lesions: consensus recommendations on terminology. Adv Dent Res. 2016 May;28(2):49-57.

Ismail AI, Pitts NB, Tellez M, Banerjee A, Deery C, Douglas G, et al.; Authors of International Caries Classification and Management System (ICCMS). The International Caries Classification and Management System (ICCMS $^{\mathrm{TM}}$ ) An Example of a Caries Management Pathway. BMC Oral Health. 2015;15(S1 Suppl 1):S9.

Last JM. A Dictionary of Epidemiology. 4th ed. New York: Oxford University press; 2001.

Maltz M, Koppe B, Jardim JJ, Alves LS, de Paula LM, Yamaguti PM, et al. Partial caries removal in deep caries lesions: a 5-year multicenter randomized controlled trial. Clin Oral Investig. 2018 Apr;22(3):1337-43.

Martignon S, Ekstrand KR, Ellwood R. Efficacy of sealing proximal early active lesions: an 18-month clinical study evaluated by conventional and subtraction radiography. Caries Res. 2006;40(5):382-8. 
Mentimeter. Interactive presentation software. [online] Available at: https://www.mentimeter.com/ [Accessed 6-7 February, 2019].

Mertz-Fairhurst EJ, Curtis JW Jr, Ergle JW, Rueggeberg FA, Adair SM. Ultraconservative and cariostatic sealed restorations: results at year 10. J Am Dent Assoc. 1998 Jan;129(1): 55-66.

Nyvad B, Baelum V. Nyvad criteria for caries lesion activity and severity assessment: a validated approach for clinical management and research. Caries Res. 2018;52(5):397-405.

Nyvad B, Fejerskov O. The caries control concept. In: Fejerskov O, Nyvad B, Kidd E, editors. Dental Caries: The disease and its clinical management. 3rd ed. Oxford: Wiley Blackwell; 2015. pp. 235-43.

Nyvad B, Machiulskiene V, Baelum V. Construct and predictive validity of clinical caries diagnostic criteria assessing lesion activity. J Dent Res. 2003 Feb;82(2):117-22.
Nyvad B, Machiulskiene V, Baelum V. Reliability of a new caries diagnostic system differentiating between active and inactive caries lesions. Caries Res. 1999 Jul-Aug;33(4):252-60.

Nyvad B, Machiulskiene V, Soviero VM, Baelum V. Visual-tactile caries diagnosis. In: Fejerskov O, Nyvad B, Kidd EA, editors. Dental Caries: The Disease and Its Clinical Management. 3rd ed. Oxford: Wiley Blackwell; 2015. pp. 191-210.

Paris S, Meyer-Lueckel H, Cölfen H, Kielbassa AM. Resin infiltration of artificial enamel caries lesions with experimental light curing resins. Dent Mater J. 2007 Jul;26(4):582-8.

Pitts N, Baez R, Diaz-Guallory C, et al. Early Childhood Caries: IAPD Bangkok Declaration. Int J Paediatr Dent. 2019 May;29(3): 384-6.

Pitts NB, Ekstrand KR; ICDAS Foundation. International Caries Detection and Assessment System (ICDAS) and its International Caries
Classification and Management System (ICCMS) - methods for staging of the caries process and enabling dentists to manage caries. Community Dent Oral Epidemiol. 2013 Feb; 41(1):e41-52.

Pitts NB, Zero DT, Marsh PD, Ekstrand K, Weintraub JA, Ramos-Gomez F, et al. Dental caries. Nat Rev Dis Primers. 2017 May;3(1):17030.

Santamaría RM, Innes NP, Machiulskiene V, Schmoeckel J, Alkilzy M, Splieth CH. Alternative Caries Management Options for Primary Molars: 2.5-Year Outcomes of a Randomised Clinical Trial. Caries Res. 2018 Jan;51(6):60514.

Thylstrup A, Bruun C, Holmen L. In vivo caries models-mechanisms for caries initiation and arrestment. Adv Dent Res. 1994 Jul;8(2): 144-57.

Wyne AH. Early childhood caries: nomenclature and case definition. Community Dent Oral Epidemiol. 1999 Oct;27(5):313-5. 